\title{
A Study of Diaphyseal Nutrient Foramina in the Adult Dried Humerus and Femur Bones
}

\author{
K C Bohra1, Priyanka Katara ${ }^{2}$, Rajesh Arora ${ }^{3}$, Chandrakala Agarwal ${ }^{4}$ \\ 1PG Resident, ${ }^{2}$ Senior Demonstrator, ${ }^{3}$ Professor, 4 Professor \& Head, \\ Department of Anatomy, SMS Medical College, Jaipur, Rajasthan, India.
}

\begin{abstract}
Introduction: Knowledge of the position of nutrient foramen in a long bone can be useful in certain orthopedics procedures. The direction of nutrient foramen in the long bones of limbs is towards the elbow and away from the knee.

Objectives: Study of nutrient foramina in humerus and femur bones of both side to obtain foraminal index.

Material and Method: In this study 62 humeri and 56 femora were taken from department of Anatomy, Sawai Man Singh medical college, Jaipur. These all were adult human cleaned and dried bones. Bones were examined for the number and location of nutrient foramina. A measuring tape, 24 gauze hypodermal needle and a magnifying hand lens were used.

Results: Most of the nutrient foramina were observed to lie on the flexor surface of the bones. Humeri showed a single nutrient foramen in $93.54 \%$ as compared to multiple nutrient foramina in $4.84 \%$, and $1.61 \%$ humeri did not show any nutrient foramen. Femora were examined possessing single
\end{abstract}

\section{INTRODUCTION}

Bones need nutrients for their dynamic growth. The three types of arteries supplying long bones are metaphyseal, epiphyseal and periosteal arteries. The main supply of nutrients to the bone is through the nutrient artery which enters it through the nutrient foramen. It is generally the branch from one or two diaphyseal arteries. Due to the difference in the growth rate of two ends of the bone ${ }^{1,2}$, the diaphyseal nutrient vessels move away from the dominant growing end. ${ }^{3}$ Nutrient foramen (NF), through which the nutrient artery enters the bone, is directed obliquely, and edges of the oblique part are elevated for entrance of the nutrient artery. 2,3

The position and the direction of the nutrient foramen vary in human long bones. The direction of nutrient foramen is towards the elbow and away from the knee. Knowledge of the position of nutrient foramen in a long bone can be useful in certain orthopedics procedures. For bone implantation this information is very fruitful. 4,5 During childhood, long bones receive about $80 \%$ of interosseous blood supply from the nutrient arteries. In case of the absence of nutrient artery the vascularization occurs through the periosteal vessels ${ }^{6}$. In bone grafts, blood supply is crucial and should be preserved in order to promote the fracture healing 7 . The nutrient vessels should be preserved as these are essential for the survival of the osteocytes in cases of tumor resection, trauma
$(96.43 \%)$ and multiple nutrient foramina $(3.57 \%)$. Foraminal index (F.I.) was calculated as 57.9 in humerus and 46.4 in femur.

Key Words: Nutrient foramina, Humerus, Femur.

\section{${ }^{*}$ Correspondence to:}

\section{Dr. KC Bohra,}

Plot No. 117, Tagore Nagar, Kartarpura, Jaipur, Rajasthan, India.

Article History:

Received: 20-07-2016, Revised: 06-08-2016, Accepted: 31-08-2016

\begin{tabular}{|l|c|}
\hline \multicolumn{2}{|c|}{ Access this article online } \\
\hline $\begin{array}{l}\text { Website: } \\
\text { www.ijmrp.com }\end{array}$ & Quick Response code \\
\hline DOI: & \\
10.21276/ijmrp.2016.2.5.024 & \\
\hline
\end{tabular}

and congenital pseudoarthrosis ${ }^{8}$. The study will be helpful in intramedullary nailing, bone grafting, treatment of fractured bones and for medico legal purposes.

Although few reports are available on morphological and topographical analysis of NF in upper limb long bones, studies on variations in the incidence, direction and position of NF in long bones of the upper limb are scarce, particularly in Indian population. The present study was thus conducted to provide information on morphology and topography of NF in humerus and femur bones of adult human.

\section{MATERIALS AND METHODS}

The material of the present study consisted of 62 humeri and 56 femora. These adult human cleaned and dried bones were obtained from the osteology collection in the Department of Anatomy, SMS medical college Jaipur, Rajasthan, India.

The location, size and number of the nutrient foramina were analyzed in each bone. Foramina smaller then a size 24 hypodermic needle were considered secondary false foramina. These foramen were not included in our study.

Total length $(\mathrm{TL})$ of different bones will be measured using plain white sheet paper and measuring tape. 
Parameter related to nutrient foramina were

1. Number of nutrient foramina.

2. Location of nutrient foramina.

3. Total length of bone.

4. Distance of nutrient foramina from the proximal end of long bone. (DNF)

The total length and DNF will be measured in $\mathrm{cm}$ to nearest $0.1 \mathrm{~cm}$.

Using above data Foraminal index (F.I.) was calculated as Foraminal Index $=\mathrm{DNF} / \mathrm{TL} \quad \mathrm{X} 100$

\section{RESULTS}

Most of the nutrient foramina were observed to lie on the flexor surface of the bones. Humeri showed a single nutrient foramen $(93.54 \%)$ compared to multiple nutrient foramina (4.84\%), and $(1.61 \%)$ humeri did not show any nutrient foramen. Femora were examined which possessed single nutrient foramen (96.43\%) and multiple nutrient foramina (3.57\%). In the $87.10 \%$ humerus, NF were located at the anterior medial surface while in the $92.86 \%$ femur linea aspera (Table 1). Average total length and of humerus and femur distance of nutrient foramina from the proximal end of long bone (DNF) were observed as per table 2 and 3 . Foraminal index (F.I.) was calculated as 57.9 in humerus and 46.4 in femur.

Table 1: Distribution of the Long Bones according to surface of Nutrient foramina

\begin{tabular}{lcc}
\hline & No. & $\%$ \\
\hline Humerus & 62 & \\
Anterior Medial Surface & 54 & 87.10 \\
Anterior Surface & 4 & 6.45 \\
Posterior Lateral Surface & 1 & 1.61 \\
$\quad$ Posterior Surface & 3 & 4.84 \\
Femur & 56 & \\
$\quad$ Lateral Surface & 3 & 5.36 \\
Linea Aspera & 52 & 92.86 \\
Medial Surface & 1 & 1.786 \\
\hline
\end{tabular}

Table 2: Total length of Adult Human humerus and femur.

\begin{tabular}{lcccccc}
\hline \multicolumn{7}{c}{ Total length } \\
\hline Bone & $\mathbf{N}$ & Mean & Std. Deviation & Minimum & Maximum & P Value \\
Femur & 56 & 43.12 & 2.538 & 38 & 48 & $<0.001$ \\
Humerus & 62 & 30.08 & 1.677 & 25 & 33 & $<0.001$ \\
\hline
\end{tabular}

Table 3: Distance of nutrient foramina from the proximal end of adult human humerus and femur.

\begin{tabular}{lcccccc}
\hline \multicolumn{7}{c}{ DNF } \\
\hline Bone & $\mathbf{N}$ & Mean & Std. Deviation & Minimum & Maximum & P Value \\
Femur & 54 & 19.97 & 4.118 & 13 & 29 & $<0.001$ \\
Humerus & 58 & 17.43 & 1.679 & 13 & 21 & $<0.001$ \\
\hline
\end{tabular}

\section{DISCUSSION}

In the present study, 62 humeri were examined. They showed a single nutrient foramen in the $93.54 \%$ humeral bones, compared to of multiple nutrient foramina (4.84 \%), and $1.61 \%$ humeri did not show any nutrient foramen. Many studies reported a percentage approximately similar to that of the present result. 1,9,10 Other studies reported a higher percentage of a single nutrient foramen (80-88\%). .111 The range of occurrence of double foramina varied from $13 \%$ (Longia et al., 1980) ${ }^{7}$ to $42 \%$ (Mysorekar, 1967) 1 . According to Kizilkanat (2007) ${ }^{11}$, the percentage of occurrence of triple foramina in the humeri did not exceed $1-7 \%$. The latter observations were in accordance to those reported in the present study. Moreover, Kizilkanat et al. (2007) ${ }^{11}$ reported the presence of four nutrient foramina in $1 \%$ of the humeri studied. Such number was not observed in the present study. On the other hand, the absence of nutrient foramina in some humeri was also reported by other authors.7,9,11,12 They stated that in such cases, the periosteal vessels were entirely responsible for the blood supply of the bone.

In this study, 56 femora were examined possessed single nutrient foramen $(96.43 \%$, and showed multiple nutrient foramina (3.57\%). Many authors stated that the majority of femora studied had double nutrient foramina, ${ }^{1,8,10,13}$ while others reported the presence of a single foramen in most specimens. $4,7,9,11,14$ Three nutrient foramina were observed in a small number of femora $(2.19 \%$ $10.7 \%$ ) by many authors. ${ }^{7-10,13,15}$ It was interesting to find studies reporting a number of nutrient foramina as high as six (Gumusburun et al., 1994) ${ }^{8}$ and up to nine (Sendemit and cimen, $1991)^{14}$, while others confirmed the absence of nutrient foramina in some femora. ${ }^{1,8}$

In this study, $87.10 \%$ of the nutrient foramina were located along the antero-medial surface, $6.45 \%$ on anterior surface, $1.61 \%$ on postero-lateral and $4.84 \%$ on posterior surface of the humerus. The foramen index ranged between $44.37 \%$ and $66.67 \%$ of the bone length. In accordance with anterior surface, previous studies reported the position of the nutrient foramina within the middle third of the bone. $1,7,10,11$ In this study, $60 \%$ of all humeral nutrient foramina were observed on the anteromedial surface of the bone. Similar findings were been reported by Longia et al. $(1980)^{7}$, Forriol Campos et al. (1987) ${ }^{10}$ and Kizilkanatet al. (2007) ${ }^{11}$. On the other hand, Mysorekar (1967) ${ }^{1}$ reported an equal percentage of foramina on both the antero-medial surface and the medial border. The site of entrance of the main artery into the humerus makes it vulnerable to be damaged in cases of exposure and plating of the medial column in supracondylar fractures of the humerus. So it had been advocated to plate these fractures both medially and 
laterally with fixation extending up to the diaphysis (Nagel, 1993) ${ }^{15}$.

In this study, $92.86 \%$ of the nutrient foramina of the femora were located mainly around the linea aspera and along a narrow strip on either side of it while $5.36 \%$ on lateral surface and $1.78 \%$ on medial surface. The foramen index ranged between $31 \%$ and $61.70 \%$ of the bone length. These results were similar to those of Laing $(1953)^{4}$, Longia et al. (1980)7, Gumusburun et al. (1994) ${ }^{8}$, Lutken $(1950)^{9}$ and Sendemir \& Cimen (1991) ${ }^{14}$ who stated that most of nutrient foramina where concentrated along the linea aspera.

Most of the nutrient foramina showed on the posterior surface of the femora. $1,7,8,13$ On the other hand, Kizilkanat et al. (2007) ${ }^{11}$ stated that most of nutrient foramina were located in the middle third with the foramen index ranging between 27 and $63 \%$ of the bone length.

Kizilkanat et al. (2007) ${ }^{11}$ stated that the position of the nutrient foramina was directly related to the requirements of a continuous blood supply to specific aspects of each bone, for example where there were major muscle attachments. It might be that, being more bulky, stronger and more active, flexors need more blood supply compared to extensors of limbs.

\section{CONCLUSION}

The present study proved that most of the nutrient foramina were observed to lie on the flexor surface of the bones. Thus, on the humerus they were mostly on the anterior surfaces while on the femur they were located on the posterior surface.

The present investigation provides additional information on the humerus and femur bone nutrient foramina. As techniques such as micro-vascular bone transfer are becoming more popular, information relating to the anatomical description of these foramina is vital to preserve the circulation of affected bony structures. It is also of relevance for those clinicians involved in surgical procedures where patency of the arterial supply to long bones is important.

\section{REFERENCES}

1. Mysorekar VR, Nandedkar AN. Diaphysial nutrient foramina in human phalanges. J Anat 1979; 128(2):315-322. 2. James Steele, Simon Mays Handedness and directional asymmetry in the long bones of the human upper limb. International Journal of Osteoarchaeology 1995; 5(1):39-49

3. Hughes, $\mathrm{H}$. The factors determining the direction of the canal for the nutrient artery in the long bones of mammals and birds. Acta Anat 1952. 15, 261-280.

4. Laing, PG. The blood supply of the femoral shaft: An anatomical study. J. Bone Jt Surg 1953. B 35, 462-466.
5. Halagatti MS, Rangasubhe P. A study of nutrient foramina in dried adult humeri of south Indian subjects. Nat J Clin Anat 2012; 1(2): $76-80$.

6. Murlimanju BV, Prashanth KU, Prabhu LV, Saralaya VV, Pai MM, Rai R. Morphological and topographical anatomy of nutrient foramina in human upper limb long bones and their surgical importance. Rom J Morphol Embryol. 2011;52(3):859-62.

7. Longia GS, Ajmani ML Saxena SK, Thomas RJ. Study of diaphyseal nutrient foramina inhuman long bones. Acta Anat (Basel) 1980;107

8. Gümüsburun E, Yücel F, Ozkan Y, Akgün Z, A study of the nutrient foramina of lower limb long bones, Surg Radiol Anat, 1994; 16(4):409-412.

9. Lutken P. Investigation into the position of the nutrient foramina and the direction of the vessel canals in the shafts of the humerus and femur in Man. Acta Anat (basel) 1950;9(1-2):57-68.

10. Forriol Campos F, Gomez Pellico I, Gianonatti Alias M, Fernandez-Valencia R. A study of the nutrient foramina in human long bones. Surg Radiol Anat 1987;9(3):251-255.

11. Kizilkanat E, Boyan N, Ozsahin ET, Soames R, Oguz O. Location, number and clinical significance of nutrient foramina in human long bones. Ann Anat 2007;189:87-95.

12. Patake SM, Mysorekar VR. Diaphysial nutrient foramina in human metacarpals and metatarsals. J anat 1977;124 (pt 2):299304.

13. Collipal E, Vargas R, Parra X, Silva H, Del Sol M, Diaphyseal nutrient foramina in the femur, tibia and fibula bones, Int $\mathrm{J}$ Morphol, 2007; 25(2):305-308.

14. Sendemir E, Cimen A. Nutrient foramina in the shafts of lower limb long bones: situation and number. Surg. Radiol. Anat. 1991;13:105-108.

15. Nagel, A. The clinical significance of the nutrient artery. Orthop. Rev. 1993, 22:557-61.

\section{Source of Support: Nil. Conflict of Interest: None Declared.}

Copyright: (c) the author(s) and publisher. IJMRP is an official publication of Ibn Sina Academy of Medieval Medicine \& Sciences, registered in 2001 under Indian Trusts Act, 1882.

This is an open access article distributed under the terms of the Creative Commons Attribution Non-commercial License, which permits unrestricted non-commercial use, distribution, and reproduction in any medium, provided the original work is properly cited.

Cite this article as: K C Bohra, Priyanka Katara, Rajesh Arora, Chandrakala Agarwal. A Study of Diaphyseal Nutrient Foramina in the Adult Dried Humerus and Femur Bones. Int $\mathrm{J}$ Med Res Prof. 2016; 2(5):121-23. 